\title{
New Programme Profiles for a New Society: An Introduction
}

\author{
Julia González, Paul D. Ryan, and Robert Wagenaar
}

Higher education is fundamental to both national ${ }^{1}$ and global contemporary knowledge economies. ${ }^{2}$ It is also a driver for social change (see for example ${ }^{3,4,5}$ ) which crucially includes making higher education available and relevant to a wider section of society and improving the mobility and relevance of its graduates in the workplace. New tools are required to integrate such developments with the sector's traditional functions of teaching and research. However, every student is different, each programme is different, each university is different and the needs of professions and nations also differ. Therefore, research leading to the development of such tools is fundamental to the development of modern society. One such tool, whose importance has recently been recognised, is the use of profiles at institutional, regional (geographic, cultural or discipline) and programme levels. Such profiles are a concise, precise and portable description of the particular academic entity. They have diverse uses ranging from ranking of institutions, aiding academic programme selection by a student, facilitating graduate mobility and as a tool for professional accreditation. We have, therefore, selected the topic of profiles for the first issue of the Tuning Journal for Higher Education. Whilst we cannot hope to cover the totality of this subject in one issue, we trust that it will stimulate debate and further promote research on the types, design and uses of profiles.

The first and perhaps the most important question we address is what should be profiled? Van Vught and Huisman discuss the importance of institutional profiles. In a world increasingly obsessed with rankings, the current metrics used ignore $97 \%$ of the world's higher education institutions

1 White House, "Education," http://www.whitehouse.gov/issues/education

2 Paul Temple, ed., Universities in the Knowledge Economy: Higher Education Organisation and Global Change (Florence KY: Routledge, Taylor \& Francis Group, 2011).

3 Australian Government's Department of Education Employment and Workplace Relations, http://www.deewr.gov.au/HigherEducation/Documents/TransformingAusHigherED.pdf

${ }^{4}$ European Commission, "The Bologna Process - Towards the European Higher Education Area," http://ec.europa.eu/education/higher-education/bologna_en.htm

5 John Brennan, "Higher Education and Social Change," Higher Education 56, no. 3 (2008): 381-93. 
and have no clear link with the quality of an individual educational programme or the needs of the student. ${ }^{6}$ Institutional profiles provide a means whereby an institution can clearly state how well it achieves its aims, thus establishing its place in a multidimensional educational hierarchy.

The matter of how to build discipline profiles is discussed by González and Yarosh. They propose a new method, which relies upon a full analysis of the core competences within a discipline. A criticism of profiles is that they can contain a long and lacklustre lists of competences, often derived from a template developed elsewhere, that fail to capture the essence of the particular discipline. Grouping these competences into interlinked groups of metacompetences and then using these groups to define a meta-profile capturing the essence of the discipline (at subject template level) or the programme (at programme profile level) requires informed debate.

Wagenaar addresses the complex issue of how decisions made in an international political forum, in this instance that of the Education Ministers of Europe, can be translated into acceptable and practical actions to be undertaken by academics. He traces the evolution of the international tools associated with the Bologna Process and analyses the difficulties in applying them at the level of a particular higher education sector or programme. He argues that the development of programme profiles requires new sectoral profiles or frameworks, which are compatible with international qualifications frameworks and discusses the evolution of such profiles, which have been developed in the framework of the recent TuningHUMART SQF project.

Profiles must be portable to be of value in the new globalized society. However, it is probably not possible or useful to try to design a single global profile for a given discipline. It is, therefore, important that the regional extent of any given profile is understood. Thus, regionalization in modern higher education is a fundamental context into which any profile must be placed. Knight analyses modern trends of regionalization in global higher education and provides a new conceptual model for its understanding.

Although all aspects of proper profile design are related to the needs of society and employability, it is important that such designs are evidence based. Avvisati, Jacotin and Vincent-Lancrin analyse the findings of two major global surveys of recent graduates. They conclude that the much sought after competence for innovation, required to drive knowledge economies, is not solely developed within Science, Technology, Engineering

6 Andrejs Rauhvargers, "Global University Rankings and Their Impact," Report. Brussels: European University Association asbl, 2011, http://www.eua.be/pubs/Global_ University_Rankings_and_Their_Impact.pdf 
and Medicine (STEM) programmes and that a research agenda is required to evaluate the best mix of skills required for its promotion.

It is impossible to consider the current reforms in global higher education without reference to the various Tuning programmes around the word. Whilst many articles make reference to the role of Tuning, that by Doná della Rose and Haug provides an overview of the profiling of higher education programmes throughout Europe from 2000 to 2011 and an assessment of its impact in Europe and beyond. The article also outlines the new challenges that now need addressing.

The final three articles deal with the progress and innovations being made by Tuning programmes around the world. Alarcón, Beneitone, de Armas, Franco, Suñé and Veneros discuss the development of a common academic credit system (CLAR) throughout 18 countries and 15 subject areas in Latin America, which is based upon level and student workload. This credit system, like the ECTS system in Europe, is essential for the portability of qualifications and the development of new interdisciplinary programmes. The careful methodology presented provides a template for those regions which do not currently have such credit systems. Hahn and Teferra present the state of higher education in Africa and review various initiatives designed to achieve harmonisation. They then present the current results of the Tuning Africa project and present the African approach to 'Tuning'. This interesting analysis of on-going work emphasises how such methodologies must adapt to serve the needs of regions in an ever-changing society. Karavayeva and Kovtun report on progress made by the Tuning Russia project. In particular they highlight the difficulties and advantages of integrating a methodology driven by academics, like the 'Tuning Method' for programme design, with Russian Federal State Education Standards. Their discussion on the need to carefully evaluate key competences and to reconcile those with the academic norms of their society provides useful insights and links nicely with the need for meta-profiles describes above by González and Yarosh.

Further research is essential. Not only do we need for each region, each profession and programme within that region (see for example ${ }^{7}$ ) and each institution globally to adopt profiling, but these profiles must be transparent and transportable. Without such a tool we face the possibility of a globalized economy only in the sense of the movement of products and services and not of expertise. However, it is the mobility of this very expertise, linked with cross-cultural and interdisciplinary innovation, upon which the new knowledge based society depends.

${ }^{7}$ European Accredited Geological Study Programmes (Euro-Ages), http://www.euroages.eu/ 